This manuscript was accepted for publication in the JOURNAL OF GEOPHYSICAL RESEARCH SOLID EARTH on 19 November 2021. This article has been accepted for publication and undergone full peer review but has not been through the copyediting, typesetting, pagination and proofreading process, which may lead to differences between this version and the Version of Record.

Please cite this article as doi: 10.1029/2021JB022768 


\title{
Multivariate statistical appraisal of regional susceptibility to induced seismicity: application to the Permian Basin, SW United States
}

\author{
Stephen P. Hicks ${ }^{1,}$, Saskia Goes ${ }^{1}$, Alexander C. Whittaker ${ }^{1}$, Peter J. Stafford ${ }^{2}$
}

1. Department of Earth Science and Engineering, Imperial College London

2. Department of Civil \& Environmental Engineering, Imperial College London

*Corresponding author (email: s.hicks@imperial.ac.uk)

\section{Abstract}

Induced earthquake sequences are typically interpreted through causal triggering mechanisms. However, studies of causality rarely consider large regions and why some regions experiencing similar anthropogenic activities remain largely aseismic. Therefore, it can be difficult to forecast seismic hazard at a regional scale. In contrast, multivariate statistical methods allow us to find the combinations of factors that correlate best with seismicity, which can help form the basis of hypotheses that can be subsequently tested with physical models. Whilst strong correlations do not necessarily equate to causality, such a statistical approach is particularly important for large regions with newly emergent seismicity comprising multiple distinct clusters and multi-faceted industrial operations. Recent induced seismicity in the Permian Basin provides an excellent test-bed for multivariate statistical analyses because the main causal industrial and geological factors driving earthquakes in the region remain highly debated. Here, we use logistic regression to retrospectively predict the spatial variation of seismicity across the western Permian Basin. We reproduce the broad distribution of seismicity using a combination of both industrial and geological factors. Our model shows that the proximity to neotectonic faults west of the Delaware Basin is the most important factor that contributes to induced seismicity. The second-most important factor is salt-water disposal at shallow depths, with hydraulic fracturing playing a less dominant role. The higher tectonic stressing, together with a poor correlation between seismicity and large-volume deep salt-water disposal wells indicates a very different mechanism of induced seismicity compared to that in Oklahoma. 


\section{Plain language summary}

Industrial operations that involve either extraction or injection of fluids deep in the ground can perturb the stress along natural weaknesses in the ground known as geological faults. This change of stress may cause earthquakes, some of which may be strong enough to be felt at the surface. The Permian Basin in West Texas has seen a recent uptick in earthquake rates, and it remains highly debated as to whether the earthquakes are mainly caused by injection of waste fluids, hydraulic fracturing for hydrocarbons, or the long-term conventional extraction of oil and gas. The vast quantity of industrial wells in the area makes it difficult to separate these factors. Without knowing these driving factors, it is difficult to forecast hazard posed by these induced earthquakes. In this study, we use a statistical technique, which often forms the basis of machine learning algorithms, to hindcast the spatial distribution of earthquake occurrence in 2017-2020 in the Permian Basin. This analysis tells us that disposal of wastewater into shallow geological formations plays a major role in causing the regional seismicity. We also find that recently-active geological faults in the region indicate a higher background tectonic stressing, which also help to drive the intense induced seismicity in the region.

\section{Key points}

- We use multivariate logistic regression to determine the factors that appear to correlate with induced seismicity in the Permian Basin.

- A combination of industrial and geological features can explain the first-order spatial distribution of seismicity.

- Shallow wastewater injection and the proximity to neotectonic faults are the main factors that correlate with the seismicity distribution. 


\section{Introduction}

Earthquakes induced by human activity can pose a significant hazard through ground shaking (e.g. Keranen \& Weingarten, 2018). Typically, induced seismicity occurs from fluid injection or extraction, causing pore-pressure diffusion (e.g. Raleigh et al., 1976), poroelastic stress changes (e.g. Segall \& Lu, 2015), or a combination of both (e.g. Zhai et al., 2019) which can change the shear stress along pre-existing faults, increasing the likelihood of triggering seismogenic slip. Industrial activities that involve fluid injection include hydraulic fracturing for shale gas/oil (hereafter, HF) (e.g. Schultz et al., 2020), geothermal well stimulation, carbon storage, and saltwater disposal (hereafter, SWD) (e.g. Ellsworth, 2013). Extraction of oil, gas, and groundwater can also induce earthquakes. Many published studies on induced seismicity have focused on the impact of changes to Coulomb failure stress due to pore pressure, poroelastic, or other indirect stress changes brought about by these industrial activities, such as reservoir compaction (e.g. van Thienen-Visser \& Breunese, 2015). Although these studies generally provide plausible mechanisms of physical triggering, due to the high level of model complexity required, they tend to focus on small regions featuring individual clusters of seismicity over sub-basin scales. Such modelling-based studies also often fail to provide information on why some regions experiencing predicted stress increases remain aseismic (e.g. Keranen et al., 2014), possibly partly because the stress increment required to nucleate seismic slip in a given pre-existing stress field is poorly understood. The occurrence of seismicity must also be modulated by natural geological controls (e.g. Keranen \& Weingarten, 2018). Such geological factors may include the presence of faults that are sufficiently large (e.g. Rubinstein \& Mahani, 2015) to produce earthquakes that can be felt or cause damage and the degree to which these faults are optimally oriented for failure (e.g. Sibson, 1990). The depth of injection/extraction may also contribute to seismicity due to variable pore pressure diffusion and stress transfer in different lithologies, depth-dependent background stress and frictional strength level (e.g. Kim, 2013), or formation overpressure effects (Ries et al., 2020). Thus, the development of effective methods to assess the susceptibility for induced seismicity, and hence seismic hazard, at a regional scale remains a key research challenge. 
Statistical approaches provide a way to address this challenge. For HF, efforts have been made to generate statistical models that can highlight the factors which increase the probability of induced seismicity (Pawley et al., 2018; Ries et al., 2020; Wozniakowska \& Eaton, 2020). In these cases, correlating well activity with induced seismicity is relatively straightforward because HF-induced seismicity is often tightly clustered around the HF injection period in space and time due to the short-lived nature of HF jobs (days to weeks), generating a highly localised pore pressure diffusion field (Savvaidis et al., 2020; Schultz et al., 2020; Skoumal, Ries, et al., 2018). In contrast, other subsurface operations in the oil and gas industry can have a much wider footprint. For example, it has been shown that earthquakes induced by multiple high-volume and high-rate SWD over periods of months to years can occur over much larger space (e.g., $>5 \mathrm{~km}$ ) and time-scales (e.g., earthquakes lagging operations by several months) (Cochran et al., 2018; Goebel et al., 2017; Norbeck \& Rubinstein, 2018; Rubinstein et al., 2018). Although efforts have been made to correlate seismicity with operations at individual SWD wells (Savvaidis et al., 2020; Teng \& Baker, 2020), any association is less straightforward than correlating HF seismicity because of the SWD's larger footprint, combined effect of multiple wells, and larger time lag. Hincks et al. (2018) used a Bayesian Network to find that the proximity of SWD wells to basement was a strong predictor of high seismic moment release in Oklahoma. This study assigned any residual correlations to a single geospatial correction parameter, so this approach was not able to fully explain the spatial distribution of induced seismicity in Oklahoma. Instead, full analysis of geological information could help to better constrain predictive models because it is believed that induced earthquakes are more likely to occur along faults that are optimally oriented in the background regional stress field, and relative to any perturbed stress change due to anthropogenic operations.

Multivariate statistical studies, such as logistic regression models, have proven useful in predicting the occurrence of other geohazards, such as landslide susceptibility (e.g. Jessee et al., 2018; Nowicki et al., 2014). However, no previous studies have exploited this approach to understand induced seismicity and to assess the role played by the different triggering factors mentioned above, across and between large regions. One disadvantage of such statistical methods is that they cannot necessarily determine the physical mechanisms of induced and triggered earthquakes because they do not include physics, such as earthquake-to- 
earthquake triggering. Yet, a statistical analysis would help us to test competing hypotheses regarding the key controls on the location and magnitude of induced seismicity, and it may ultimately enable us to forecast the potential for induced seismicity to occur in given areas.

Recent emergent seismicity in the western Permian Basin, Texas (e.g., Frohlich et al., 2020; Robinson et al., 2020; Savvaidis et al., 2020; Skoumal et al., 2020; Skoumal \& Trugman, 2021; Staniewicz et al., 2020; Trugman \& Savvaidis, 2021) provides a new opportunity to understand the fundamental drivers of induced seismicity in this region, and whether these factors are similar to, or differ from, other regions of extensive induced seismicity, such as in Oklahoma. Seismicity is very spatially clustered in the western Permian Basin (Figure 1a). Since 2017, most seismicity has been concentrated in Reeves and Pecos counties (Frohlich et al., 2020), which we refer to as the "Pecos cluster" in this paper. Earthquakes in the Pecos cluster appear to occur in northwest-southeast trending lineations, and they have generally been low in magnitude with the largest event to date being $M\llcorner 3.8$. To the northwest of the Pecos cluster, there was an emergent zone of seismicity in late 2019 which culminated in a $M_{w}$ 4.8-5.0 earthquake in February 2020 in the Mentone area (Tung et al., 2020). To the west of the Mentone area, there is another intense area of generally low-magnitude seismicity (the "Culberson cluster") which appears to occur a long distance from the densest area of well activity (Figure 1a); (Skoumal et al., 2020). In contrast, the northern portion of the Delaware Basin, which lies in south-eastern New Mexico, appears mostly aseismic, as does the Central Basin Platform. Further east, in the western part of the Midland Basin, there is a distinct cluster of earthquakes close to the cities of Odessa and Midland, which we call the "Odessa cluster". The Odessa cluster appeared to emerge in late 2018 - early 2019. In Oklahoma, near-basement injection clearly induces most seismicity; however, it remains highly debated as to whether earthquakes in the western Permian Basin are primarily influenced by deep SWD into the Ellenburger Group (Lemons et al., 2019; Skoumal et al., 2020; Tung et al., 2020), HF in the Wolfcamp Group (Savvaidis et al., 2020), shallow SWD into the Delaware Mountain Group (Deng et al., 2020; Zhai et al., 2021), or conventional production of hydrocarbons at shallow depth (Deng et al., 2020; Doser et al., 1991, 1992). Moreover, in much of the Permian Basin, there has been production of hydrocarbons from shallow formations, such as the Delaware 
Mountain Group and Bone Spring Group, since the 1970s, which may affect the preexisting state of stress (Dvory \& Zoback, 2021). Hypocentre depths also remain uncertain over the region due to a combined effect of uncertain velocity models station distribution, unclear direct arrivals due to complex subsurface structure, and high anthropogenic noise levels due to industrial activity (Lomax \& Savvaidis, 2019; Skoumal et al., 2020). Operational earthquake locations from the TexNet network suggest that most earthquakes occur at near-basement depths of 6-8 km (Savvaidis et al., 2019), although there is a lot of scatter (Figure S1). However, more recent analysis for earthquakes close to the boundary between Reeves and Pecos counties suggest shallower hypocentre depths of $1-3 \mathrm{~km}$ depth, consistent with the depths of the Delaware Mountain and Bone Spring Groups (Dvory \& Zoback, 2021; Yixiao Sheng et al., 2020). When we consider multi-faceted operations across a range of depths, together with hypocentre depth uncertainty, and the lack of detailed hydrogeological models for specific areas, we find that it is not easy to separate the different factors and their effect on seismicity. Another potential key difference between induced seismicity in Oklahoma and the western Permian Basin is the presence of numerous north-south striking mid-to-late Quaternary faults lying 30-50 $\mathrm{km}$ west of the edge of the Delaware Basin (Figure 1a). These faults belong to the West Delaware Mountain Fault Zone, which strike to the WSW, have a normal sense of offset, and slip at a rate of less than $0.2 \mathrm{~mm} /$ year (Collins et al., 1996). These recently active faults may indicate stronger neo-tectonic stresses compared with the Oklahoma region.

Although there have been several recent studies on seismicity in the Delaware Basin (e.g. Skoumal et al., 2020, 2021; Tung et al., 2020; Zhai et al., 2021), they have tended to focus on the individual clusters described above rather than taking a holistic view of seismicity across the whole area. Our focus in this paper is to use a statistical approach which can help to identify broad correlations that help to hindcast the spatial evolution of seismicity over the large area. The spatial variability of seismicity across the western Permian Basin, and particularly the Culberson cluster which occurs far away from SWD wells, provides us with a unique opportunity to carry out a large-scale statistically-driven analysis of what the combined geological and industrial controls are surrounding induced seismicity in this region. 
In this study, we use logistic regression analysis to model the spatial distribution of earthquake occurrence between 2017 and 2020 across the western Permian Basin. We uniquely combine geological factors with industrial variables based on detailed datasets of fluid injection and extraction from hundreds of thousands of wells in the region. Whilst correlation does not necessarily mean causation, and because our approach takes a time-integrated view and cannot model the effects of all factors that trigger earthquakes (for example, earthquake-to-earthquake triggering), our resulting logistic regression model demonstrates that the main zones of seismicity in the Permian Basin can be robustly modelled using a small number of both industrial and geological features. 
a

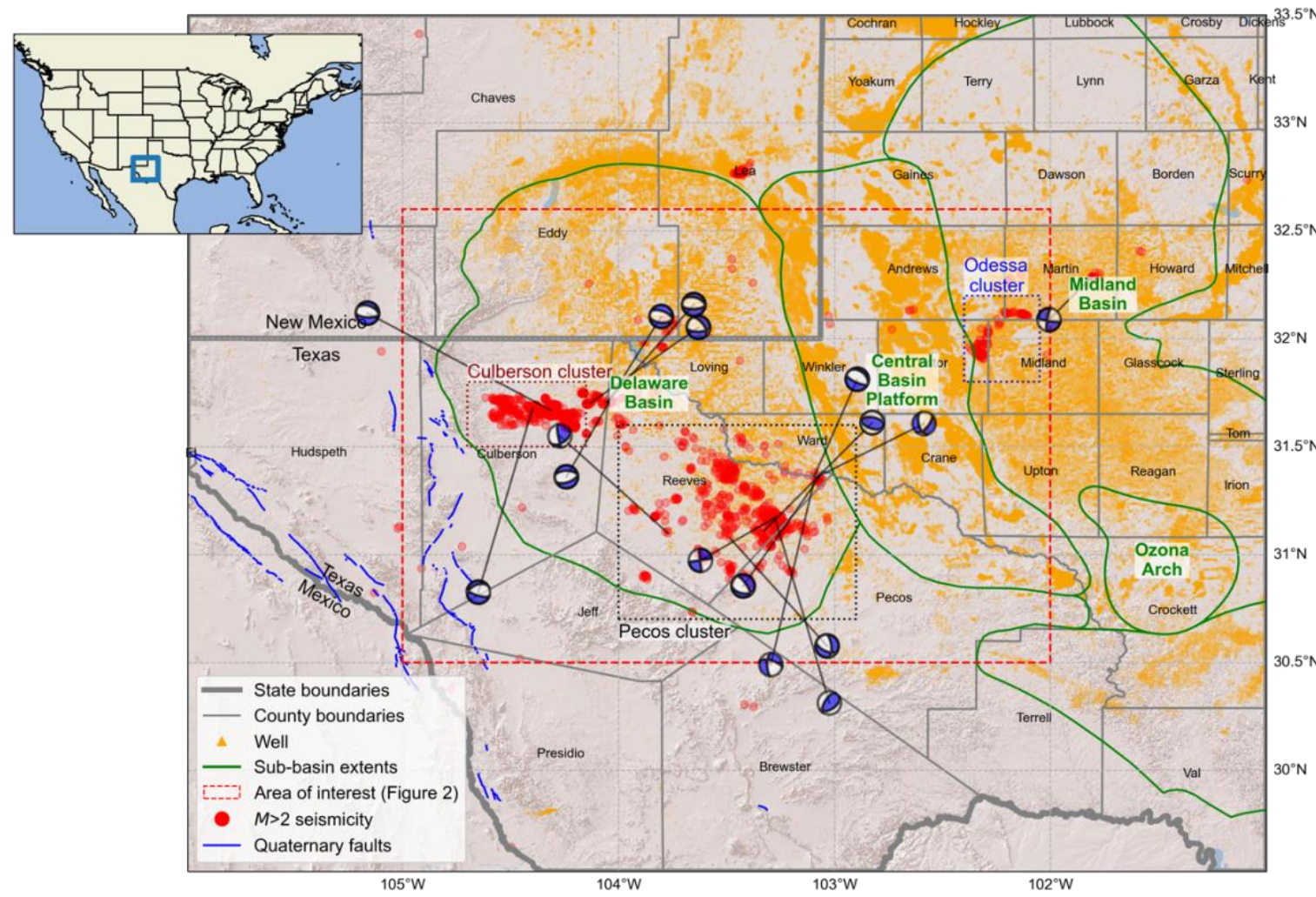

b

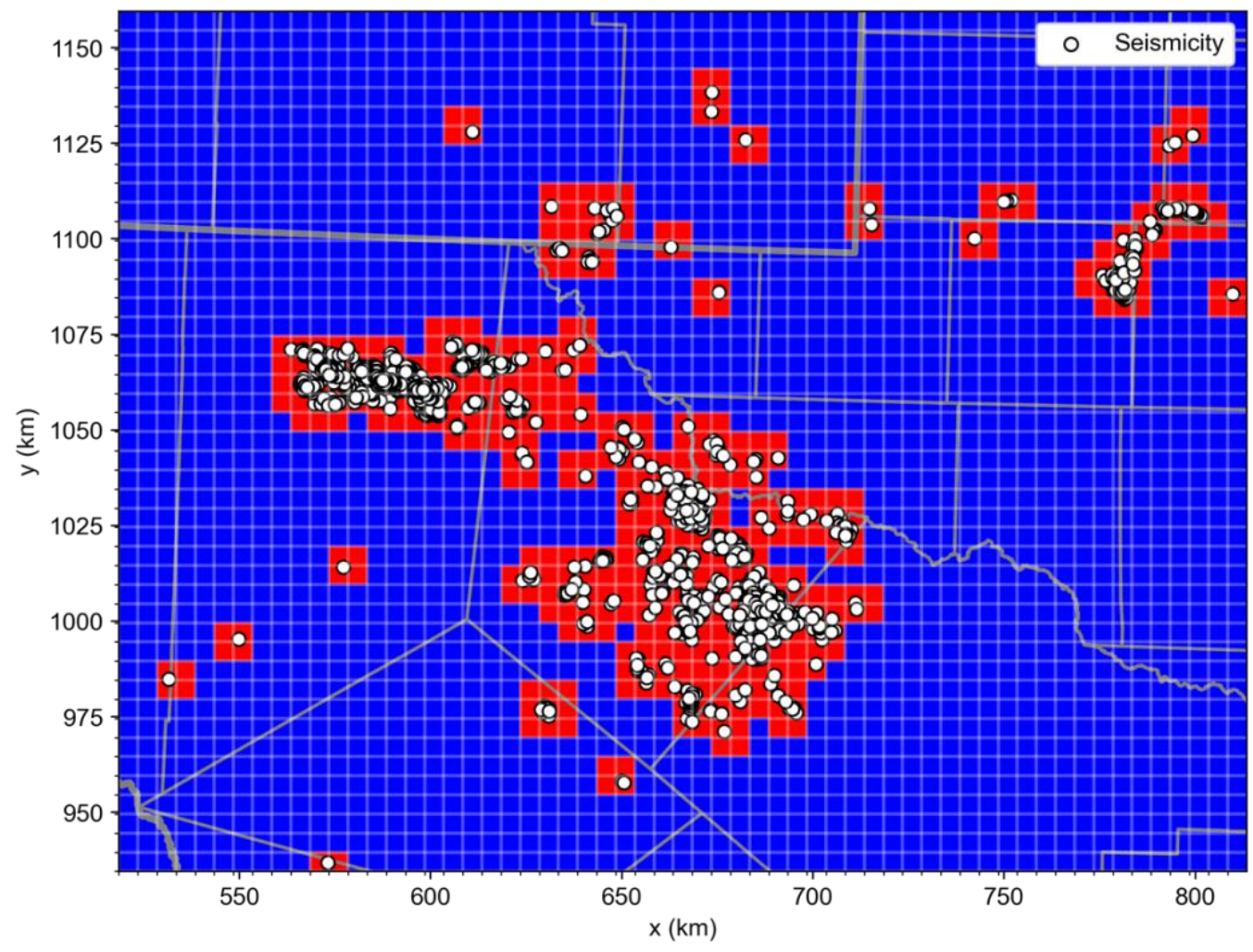

Figure 1: a) Geographical overview of the western Permian Basin. Showing the main features of the basin, seismicity, with focal mechanisms plotted [from the TexNet

(Savvaidis et al., 2019) and New Mexico Tech catalogues], and the locations of all 492,000 wells in the IHS-Markit database which are used in this study. The area of interest is outlined. County names are labelled. The location of this map is shown by the blue box in the inset.

Earthquake locations and focal mechanisms from the TexNet catalogue. b) Our target variable of earthquake occurrence with the area defined by the red dashed line in (a). The white lines show the target grid, with a spacing of $5 \mathrm{~km}$. Grey lines denote state and county boundaries. Note the difference in map projections between (a) and (b). 


\section{Feature design and logistic regression method}

\subsection{Target variable: earthquake occurrence}

Our earthquake database comes from the TexNet catalogue (Savvaidis et al., 2019). The TexNet catalogue starts in January 2017. We do not include pre-2017 seismicity from the USGS ComCat catalogue due to inherent epicentral uncertainties prior to installation of regional seismic monitoring networks. Since our area of interest (hereafter, Aol) also covers south-eastern New Mexico, we supplement the TexNet dataset with additional events reported by the New Mexico Tech Seismological Observatory (Pankow et al., 2019). Although the magnitude of completeness $\left(M_{c}\right)$ in certain areas across the Aol reaches as low as $M L 1.2$ (Savvaidis et al., 2019), given that our Aol covers areas away from the main seismicity clusters and that we merge two catalogues, we opt for a more conservative $M_{c}$ of 2.2, based on these considerations, together with formal assessment of departures from a regional Gutenberg-Richter distribution. To start with, we generate a target variable based on seismicity, which represents the spatial distribution of earthquake occurrence. We divide up the Aol, use the NAD83 / Texas State Mapping System (EPSG:3081) projected coordinate system, with a uniform spacing in the $x$ and $y$ directions of $5 \mathrm{~km}$ (Figure 1b). We choose this grid spacing because it remains larger than the typical one-sigma epicentral errors and it allows us to define a minimum search radius for industrial activity of $5 \mathrm{~km}$ (see Section 2.2).

We assign each grid node a value of one if at least one $M L>2.2$ earthquake has occurred within $5 \mathrm{~km}$ of the central point of each grid square since 2017. Otherwise, if no earthquakes locate within that grid node, we assign a value of zero. Using this distance kernel ensures a smoother distribution of seismicity that does not suffer from artifacts caused by epicentres lying close to the edge of a grid square. The resulting binary 2-D grid of the earthquake occurrence target feature is shown in Figure 1b, and is similar to that used by Ries et al. (2020) used to study HF induced seismicity in Oklahoma. One advantage of using this binary target variable is that it avoids the need to decluster the seismicity catalogue. In addition, our approach negates the need to use earthquake depths, which remain highly uncertain in the region (e.g. Savvaidis et al., 2019), and do not correlate directly with depths of fluid 
injection and extraction (Figure S1). In our target grid, $16 \%$ of the 2,655 grid points are assigned the value " 1 ".

\subsection{Candidate predictive features}

Our model features include both industrial data provided by the IHS Markit database (see Data availability statement) and a range of geological data, as described below.

\section{Geological features}

We use a set of geological features that includes depth-to-basement (Figure 2a), because basement depth has been found to be an important factor seismicity induced by SWD and HF (Hincks et al., 2018; Skoumal, Brudzinski, et al., 2018). We also use information about pre-existing faults and their stress state. In the western Permian Basin, there is a normal faulting stress regime, as indicated by an Anderson fault shape parameter (Simpson, 1997), $A_{\Phi}=0.5-0.9$ (Lund Snee \& Zoback, 2016, 2020); (Figure 2b). Further to the east, the stress regime becomes a mixture of strike-slip and normal faulting. Overall, the predominance of normal faulting means we can use orientations of the maximum horizontal compressive stress ( $S_{H \max }$ ) from the same studies as above (Figure $2 \mathrm{c}$ ), to derive a simple proxy of how optimally oriented faults are to failure. We do not have adequate constraints on fault dip angles to derive a more quantitative slip tendency value. We use a variety of faults datasets to derive smoothly varying fields of fault strike to compute the cosine of the angular difference between $S_{H \max }$ and a fault strikes for a variety of fault datasets in the region. $S_{H \max }$ orientations align quite strongly with lineations of seismicity in the Delaware Basin (Figure 2c), supporting the use of this angular difference metric. 

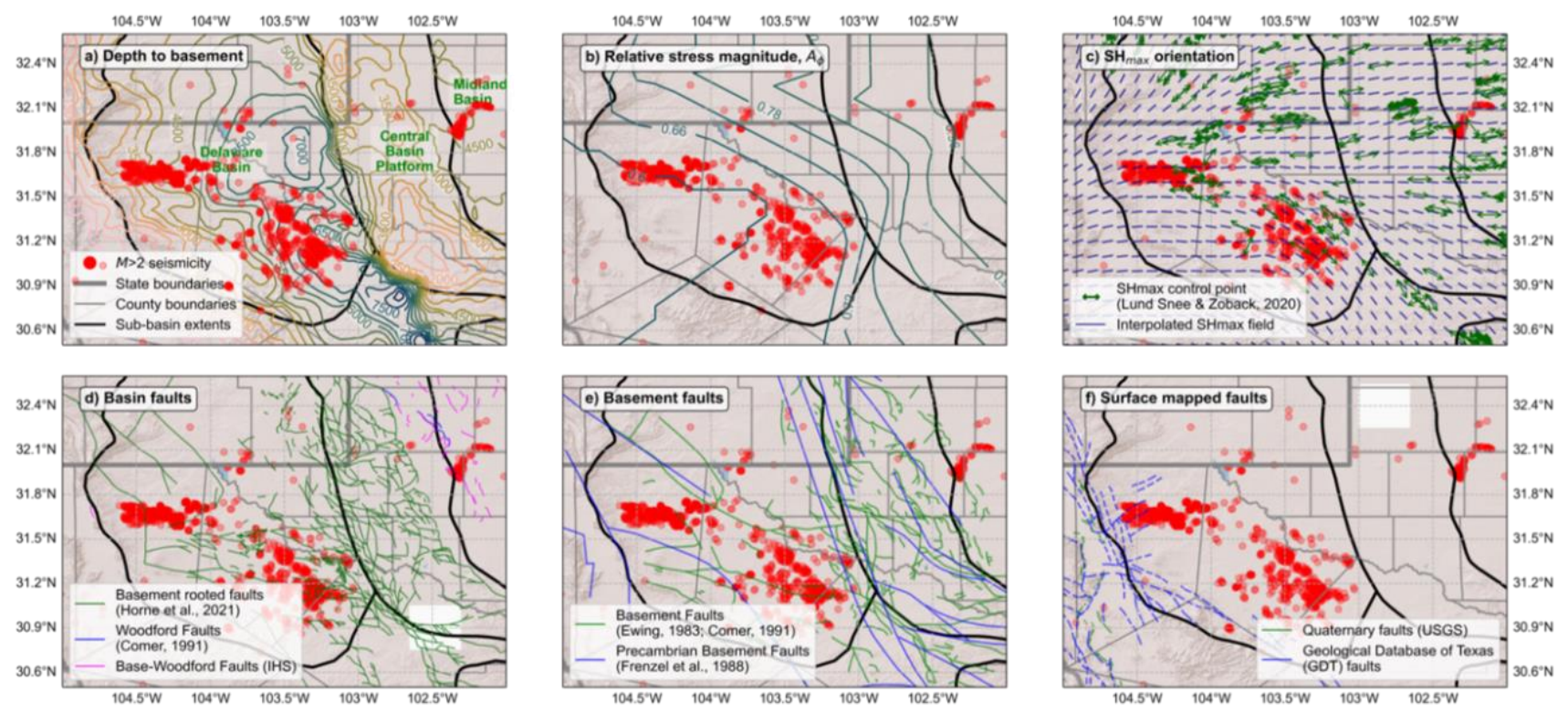

Figure 2: Geological context showing variation in basin structure, stress, and faulting structures. Symbols shown in all plots are given only in the legend of Panel (a). a) Basin thickness given in meters. b) Contours of relative stress magnitude, $A_{\Phi}$, based on Lund Snee and Zoback (2016), illustrating the regional dominance of normal faulting. c) Spatially smoothed distribution of $S_{H \max }$ orientations, based on well observations (Lund Snee \& Zoback, 2016, 2020). Distribution of faults mapped within the basin (d) and in the basement (e). f) Surface faults, including neo-tectonic structures.

For subsurface faults within the Permian Basin, we use the recent basement-rooted fault database of Horne et al. (2021). For areas outside the study area of Horne et al. (2021), we include faults in the Woodford formation from Comer (1991); (see Figure 2d). We also include a database of Precambrian basement structures from Ewing (1983) and Comer (1991); (see Figure 2e). These maps of subsurface faults are largely derived by well correlations and stratigraphic thickness changes rather than direct imaging. For each grid point, we compute both a minimum distance to nearby faults, as well as a smoothed mean fault strike and $S_{H \max }$ azimuth. We then compute the cosine of the resulting angular difference between $S_{H \max }$ and fault strike with lower values indicating a more optimal fault orientation. Whilst such fault maps are likely to be spatially incomplete, our smoothing approach captures the broad variation in fault orientations across the Aol governed by control points where fault data are available. Finally, given the proximity of the active Rio Grande rift system, $\sim 150 \mathrm{~km}$ to the west of the western boundary of the Delaware Basin, we use the USGS Quaternary Faults database (Figure 2f); (Collins et al., 1996) to compute the distance between each grid point and the closest recently active fault, as a simplified proxy for pre-existing tectonic stress. 


\section{Industrial features}

We use well metadata and corresponding injection and extraction time series data for wells in the study area of the western Permian Basin from the commercial Production-Allocated and Well database provided by IHS Markit (see Data Availability statement). The well metadata used comprise well locations, total vertical depths, and formation top at total depth information. The time series data comprise fluid (oil, gas, water) extraction and injection volumes given to a month-level resolution. These data are originally based on operational data reported by the regulator, the Railroad Commission of Texas (RRC). The locations of injection and extraction wells are shown in Figure 3. We supplement this dataset with HF data reported by the FracFocus database (Dundon et al., 2015); (Figure 3b). We include data for all wells for the geographic area of interest (Aol) covering $\sim 70,000 \mathrm{~km}^{2}$ (Figure 1). We include monthly injection and extraction data from January 2017 up until July 2020 to ensure sufficient regional geographic data completeness across all wells, and so that this timeframe coincides with the seismicity dataset. We tested whether the inclusion of operational data from prior to 2017 affected results; however, these data are highly correlated with the post-2017 data, so were not included as a separate feature. This spatial correlation over different time periods means that recent industrial activity is representative of operations over a longer period, even if contemporary seismicity may be driven by a build-up of industrial operations over time. The approach of using post-2017 data broadly represents recent fluid injection and extractions rates, the former of which has been shown to correlate with seismicity in Oklahoma (e.g. Keranen et al., 2014).

For fluid injection and extraction volumes, we compute total cumulative monthly volumes within a given circular radius from the centre point of each grid point. We consider three possible search radii of $5 \mathrm{~km}$ (i.e., the grid spacing), $10 \mathrm{~km}$ and 25 $\mathrm{km}$. These length scales were chosen to be representative of distances relevant for near-field direct pore pressure effects and longer-distance poroelastic triggering due to different industrial operations. For HF, we use a single distance of $5 \mathrm{~km}$, consistent with pore pressure effects from short-lived injection (Ries et al., 2020; Schultz et al., 2020). For SWD, we also use the larger distances of 10 and $25 \mathrm{~km}$ to encompass coupled pore pressure and longer-range poroelastic effects (e.g. Goebel et al., 2017). Based on the interpreted well formation tops at total depth from IHS's 
PRODFIT database, we divide up the injection and extraction volumes into 3 different groups: "Shallow", "Wolfcamp" and "Deep". We do this because of the variable injection and extraction volumes at different depths in the Permian Basin (Figure S1). The Shallow group includes the upper Permian and Triassic formations, such as the Delaware Mountain Group and Bone Spring Group in the Delaware Basin. Wolfcamp refers to the Lower Permian Wolfcamp Shales, which are hydraulically fractured for hydrocarbons. Deep corresponds to deeper, sub-Permian formations, such as Carboniferous, Devonian, and Silurian formations. For SWD, we include a further feature of total injection occurring at greater than 2,000 m depth and where the injection depth is within $1,000 \mathrm{~m}$ of the top-basement, since that is a factor believed to strongly drive seismicity in Oklahoma (Hincks et al., 2018). The locations of wells which inject into deep and shallow formations are shown in Figure $3 \mathrm{c}$ and Figure $3 \mathrm{~d}$, respectively. For HF, we compute both the total number of frac jobs within $10 \mathrm{~km}$ each grid point as well as the total volume injected.
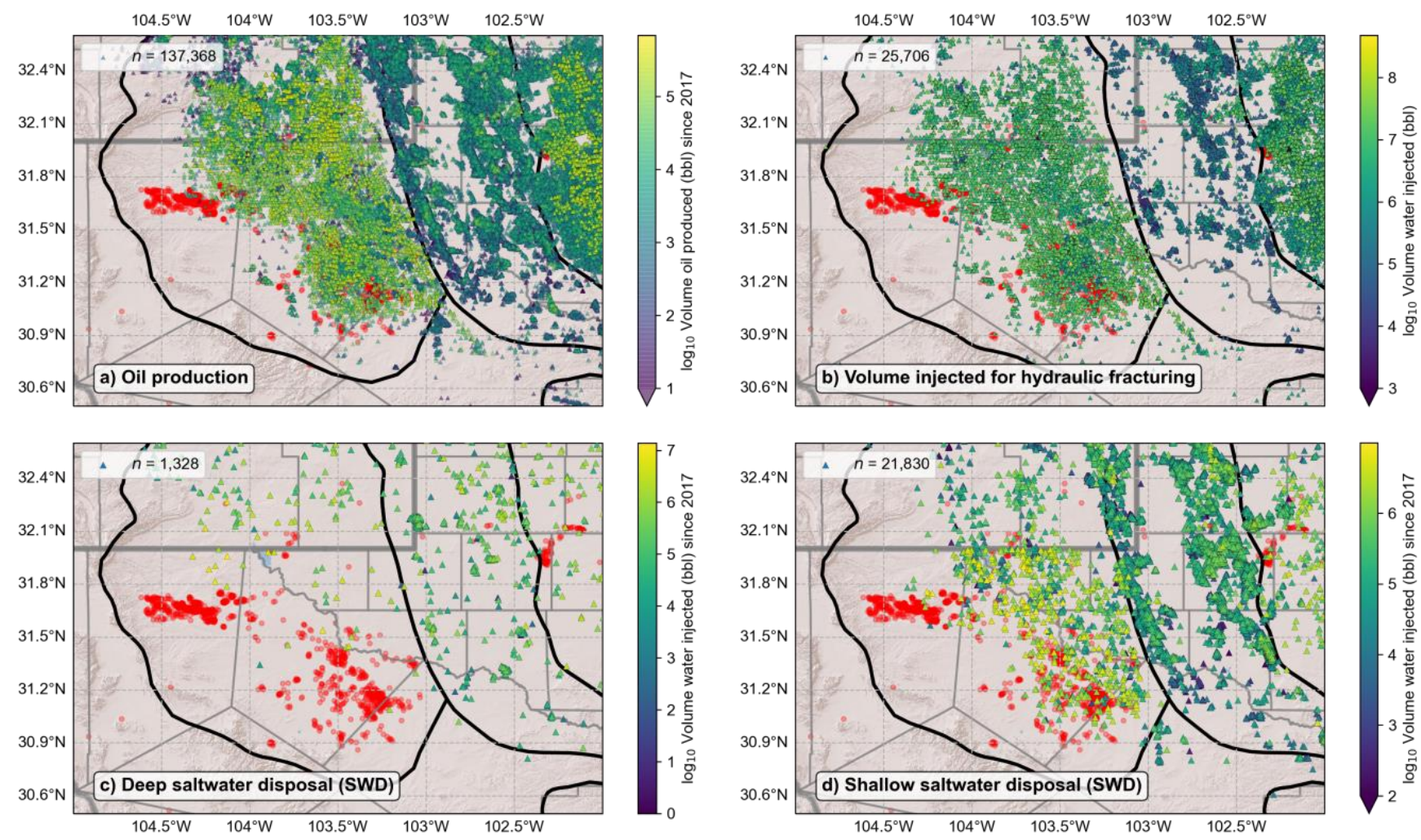

Figure 3: Industrial context showing individual well volumes for (a) fluid extraction (b), HF stimulation (c) deep SWD, and d) shallow SWD, and (d) hydraulic fracturing volumes since 2017 . The triangles correspond to individual wells, with their fill colour indicating fluid volume. $M_{L}>2$ seismicity is shown as red circles. The legend shows the number of wells plotted in each panel. 


\subsection{Logistic regression workflow}

Binary variables, like our target feature of earthquake occurrence, can be fit using models of logistic regression (LR) (e.g. Cox, 1958; James et al., 2013). LR is a simple yet powerful statistical function using a linear model to predict the log-odds ratio of a binary outcome ("target variable"). The linear model is expressed as linear combination of multivariate input data ("features"). A LR approach is adopted because we need to consider a large number of factors that have already been linked to causing induced seismicity in the Permian Basin (e.g. Dvory \& Zoback, 2021; Savvaidis et al., 2020; Skoumal et al., 2020; Tung et al., 2020; Zhai et al., 2021). Also, it can be seen from Figure 3 and Figure 4 that there is no strong relationship of individual industrial operations or geological features with seismicity, showing that a multivariate approach is required.

We standardise and normalise all input features using the Yeo-Johnson power transform (Yeo \& Johnson, 2000) (hereafter, YJ) to reduce data skewness and to make it more Gaussian-like, which is important for variables such as injection volumes which cover many orders of magnitude, as well as zero values. The normalisation of features allows us to interpret the relative difference in the model coefficients. Here, it is worth noting that the $\mathrm{YJ}$ transformation does not allow us to easily analyse absolute values, such as fluid volumes. Examples of raw and transformed features are shown in Figure 4.

As some industrial activities strongly overlap in space, they cannot be effectively distinguished due to high collinearity. We calculated feature similarity using a clustered matrix based on Pearson correlation coefficients computed on the transformed features (Fig. 5). Where features are strongly colinear we removed, grouped, and renamed certain features to account for this. One key example is SWD and production from shallow layers, which share a correlation coefficient of 0.9 (Figure 5). We therefore group these features, use a single feature, and rename them to "Shallow injection / Extraction". 

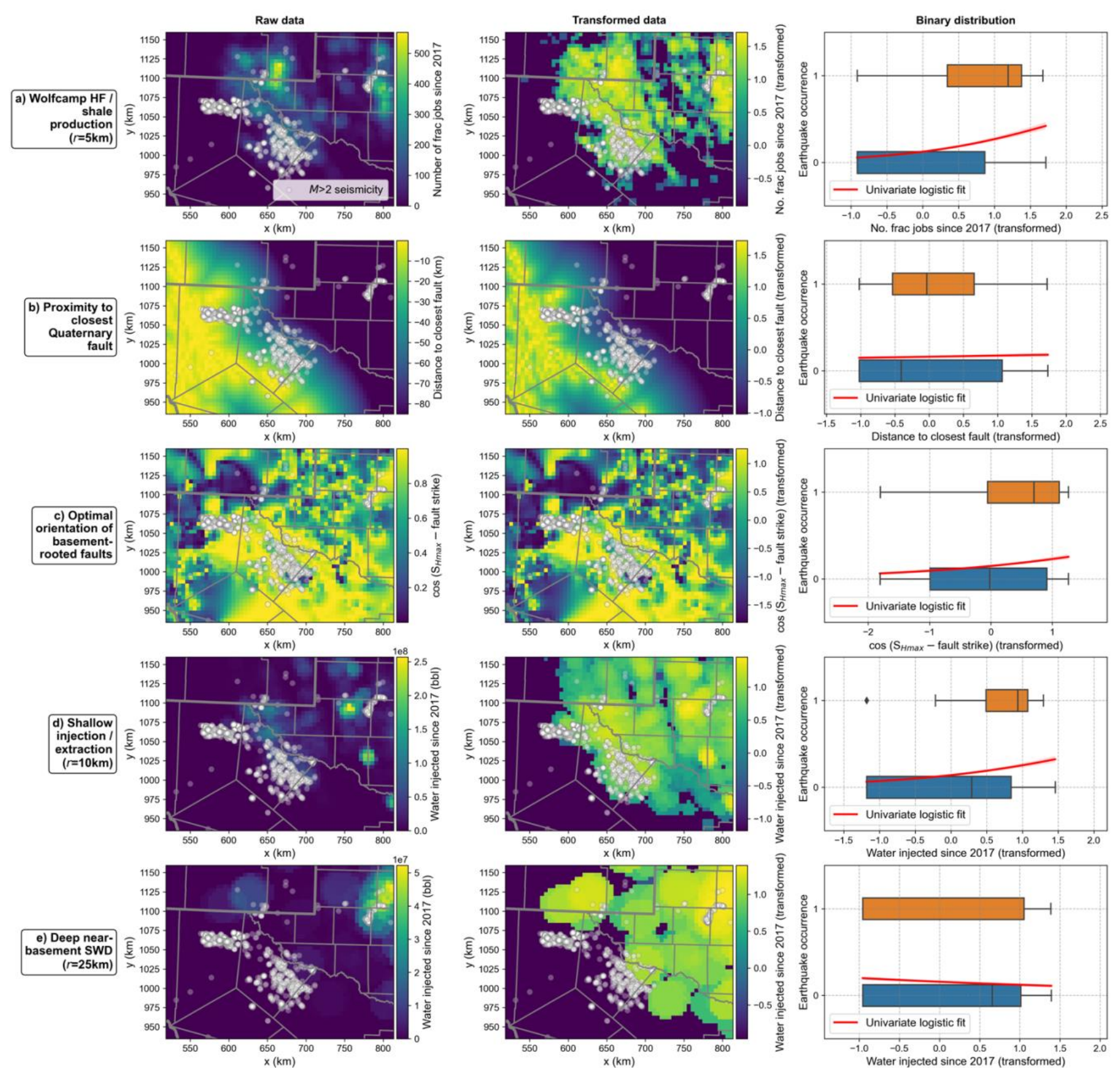

Figure 4: Distributions of input candidate features that are significant in our regression model. The left-hand panel shows the spatial distribution of original data (left), whilst the central panel shows the standardised and transformed data. These maps are projected in the NAD27 (epsg3081) coordinate system. The grid spacing of our model is indicating by the pixels in the maps. The right-hand panel shows the distribution of the transformed feature values (as expressed as boxand-whisker diagrams) for cases of both positive and negative earthquake occurrence, with a univariate logistic regression fit given by the red line. Examples of other features are shown in Figure S2. 


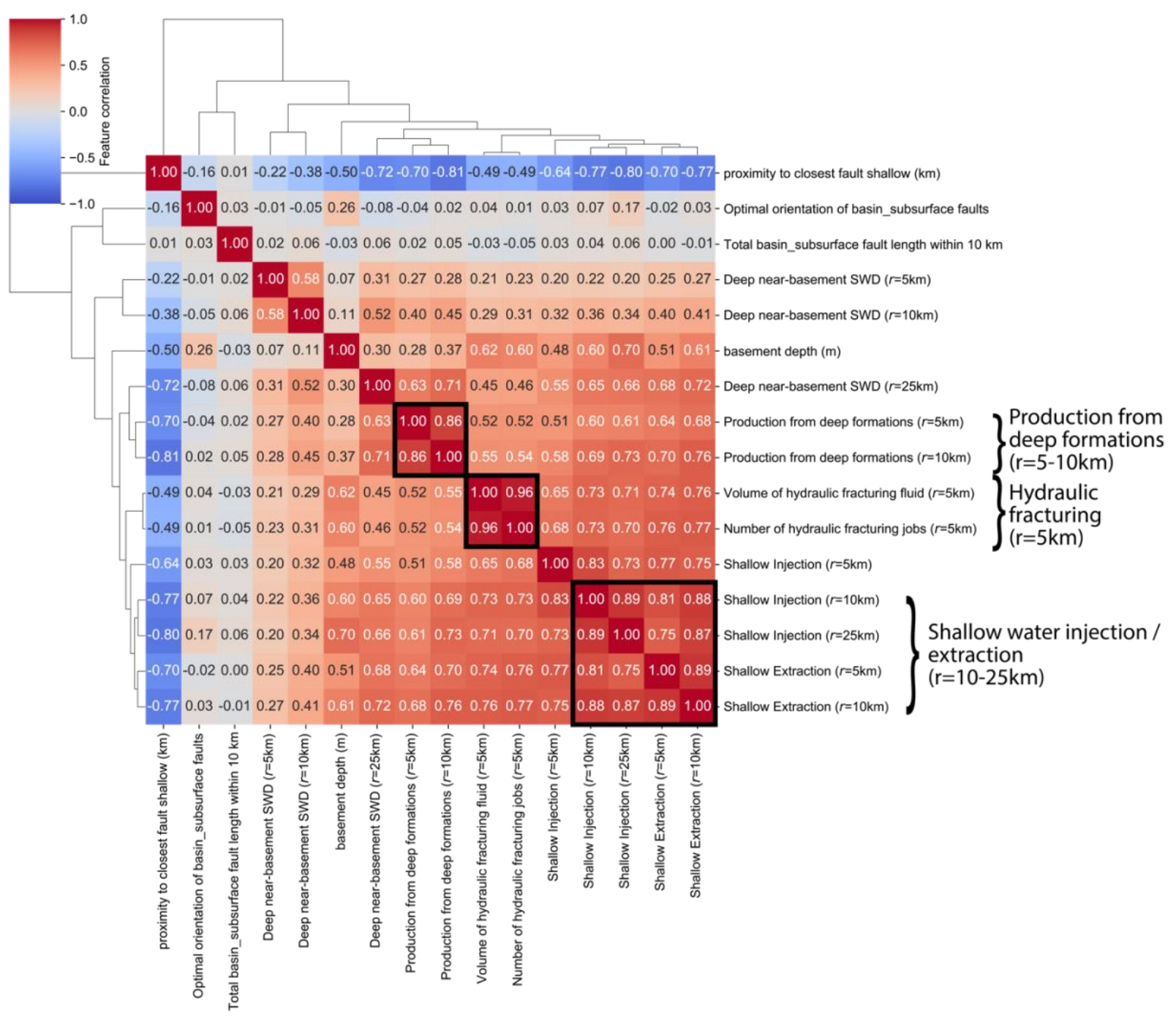

Figure 5: Feature similarity. Clustered matrix based on Pearson correlation coefficients computed on the transformed features. Number inside each block show the correlation value. A dendrogram along the top of the plot shows hierarchical clustering. Highly similar feature groups are shown by black boxes and the group label is given to the right of the plot.

We generate a LR model with a forward stepwise approach, in which we iteratively add in feature variables whilst ensuring that the $p$-value of each new feature remains below 0.05 (Ries et al., 2020; Teng \& Baker, 2020) to ensure that each feature is statistically significant at the $95 \%$ confidence level (e.g. Nowicki et al., 2014). This process eliminates insignificant features but still does not account for high collinearity between variables. For example, in the case where the spatial distribution of fluid injected into the Wolfcamp Shales for HF strongly correlates with the location of oil produced from the same formation, so we compute the Variance Inflation Factor 
(VIF) (Jessee et al., 2018; Midi et al., 2010) for each feature and iteratively remove the most colinear variable over a given number of steps. The number of steps we choose to remove features for is based on manual assessment of several fit-quality parameters. These are described as follows: (1) The F1 score which accounts for model precision and recall, especially due to the large class imbalance (more true negatives than true positives) for our target feature (e.g., Chicco \& Jurman, 2020). (2) The AUROC (area under the receiver operating characteristic) score which is a metric for the model's ability to discriminate between classes (e.g., Fawcett, 2006). (3) The model's pseudo- $r^{2}$ score $\left(r^{2} p\right)$ (McFadden, 1973), which measures the amount of variance explained by the logistic regression model. (4) Akaike's Information Criterion (AIC) (Akaike, 1974). (5) The Bayesian Information Criterion (BIC) (Schwarz, 1978). AIC and BIC assess model fit by penalising the inclusion of additional variables. Smaller values of AIC and BIC indicate a better-performing regression model based on log-likelihood and complexity. (6) Moran's I-number on the model residuals $\left(M I_{r}\right)$ (Moran, 1950), which measures the extent to which the model residuals are spatially correlated. We also ensure that the maximum feature VIF does not exceed 5, a commonly used cut-off in regression studies (e.g. Stine, 1995). Visual inspection of the feature correlation matrix (Figure 5) verifies that this approach successfully eliminates highly colinear variables with a correlation coefficient of $>0.8$. 


\section{Results}

In this section, we consider the performance of different model classes in terms of the values of various fit-quality parameters described in the preceding section ( $F 1$ score, AUROC score, $r^{2} p$, AIC, BIC, and MIr). These parameter results from the different models considered in this section are shown in

Table 1.

\subsection{Null hypothesis - univariate regression using SWD}

As a first step to explore which operational parameters best fit the earthquake occurrence target variable, we first test the null hypothesis that deep SWD is a primary influence on seismicity, as has been inferred for Oklahoma (e.g. Goebel et al., 2017; Hincks et al., 2018), and has been proposed for the Delaware Basin (Savvaidis et al., 2020; Skoumal et al., 2020, 2021; Tung et al., 2021). We therefore perform univariate regression using deep SWD feature only to test this hypothesis.

Deep SWD is a very poor predictor of the spatial distribution of earthquake occurrence, as it is unable to model any of the observed locations of earthquake occurrence $(F 1$-score $=0.0)$, and the $r^{2} p$ is very small $(0.02)($

Table 1). This result arises because in the study area, the highest SWD volumes mostly lie to the north of the main seismicity clusters, as seen through both the distribution of individual high-volume disposal wells (Figure 3c) and the summed contribution from multiple wells (Figure 4e). This finding suggests that we can confidently reject the null hypothesis that, on its own, deep SWD volume is a predictor of the spatial distribution of seismicity throughout the western Permian Basin. Even with the possibility of a near-field aseismic zone and a longerwavelength triggering hypothesis, associated with deep SWD wells (Goebel et al., 2017; Guglielmi et al., 2015), does not seem to be supported by the location of highvolume disposal wells relative to the main clusters of seismicity.

Other univariate regressions were also performed (Figure 4), and no individual feature demonstrated strong predictive performance on its own. 


\subsection{Optimum multivariate regression model}

Given the clear rejection of the null hypothesis that deep SWD correlates with seismicity, we compute the best fitting LR model using a combination of geological and industrial features for a more thorough exploration of the solution space. The results of this model are shown in Figure 6.

We test the data-dependent robustness of this model through a bootstrap approach in which we randomly remove $20 \%$ of the input data grid points and repeat this process 2,000 times to generate uncertainties in the resulting model coefficients. This test allows us to assess the sensitivity of the model to small variations in the distribution of earthquake occurrence. These uncertainties are shown as histograms in Figure 6b, and show that all significant features in the optimum model are robust, with very little contribution from the features that do not feature in the optimum model. Although we do not have a sufficiently large seismicity dataset to generate a training, testing, and validation data subsets, this Bootstrap resampling shows that we are not overfitting the data. We also compute the standard errors in the output model using the delta method, which uses a Taylor series expansion of the inverse logit function of the regression. The upper and lower confidence interval in the binary model space is shown in Figure 6c.

Our model reproduces the main cluster of seismicity in the Delaware Basin, and within upper and lower confidence intervals (Figure 6a,c). Both industrial and geological features are needed to accurately hindcast the main clusters of seismicity. The normalised coefficients of the model features are shown in Figure $6 \mathrm{~b}$. We discuss each of these features in the Discussion section. By testing a smaller Aol covering the Pecos and Reeves seismicity clusters in the Delaware Basin, we find that these relative feature coefficients are stable and insensitive to the exact definition of the Aol (Figure S3). The distance to quaternary faults is the most important feature of the LR model. With Quaternary Faults lying 30-40 km from the western edge of the Delaware Basin (Figure 1a; Figure 2f), indicating a higher neotectonic stressing rate than in Oklahoma, we thought it plausible that the distance to the closest quaternary fault feature would help to reproduce the seismicity at the western edge of the Culberson cluster. However, our LR model shows that we are still unable to reproduce the westernmost edge of seismicity in the Culberson cluster, highlighting that we are perhaps missing features, such as inter-earthquake 
triggering, which may also be specific to certain regions. Alternatively, a fault zone with very high diffusivity could allow long-range earthquake triggering in such a way that is not captured by our approach of assuming a spherically constant search radius. The second-most important industrial feature is SWD into shallow formations. The model's $r_{p}^{2}$ of 0.37 indicates that the model has fair predictive power (approximately equivalent to a traditional $r^{2}$ value of $\sim 0.65$ (Domencich \& McFadden, 1975). We are unable to recover the Odessa cluster of seismicity which indicates that the causative factors of seismicity across the Permian Basin vary spatially. In other words, the factors causing seismicity in the Midland Basin are different to those in the Delaware Basin. We are also unable to recover small clusters of seismicity in the northern parts of the Delaware Basin and Central Basin Platform, in the NewMexico - Texas border region.

a) Optimum model prediction
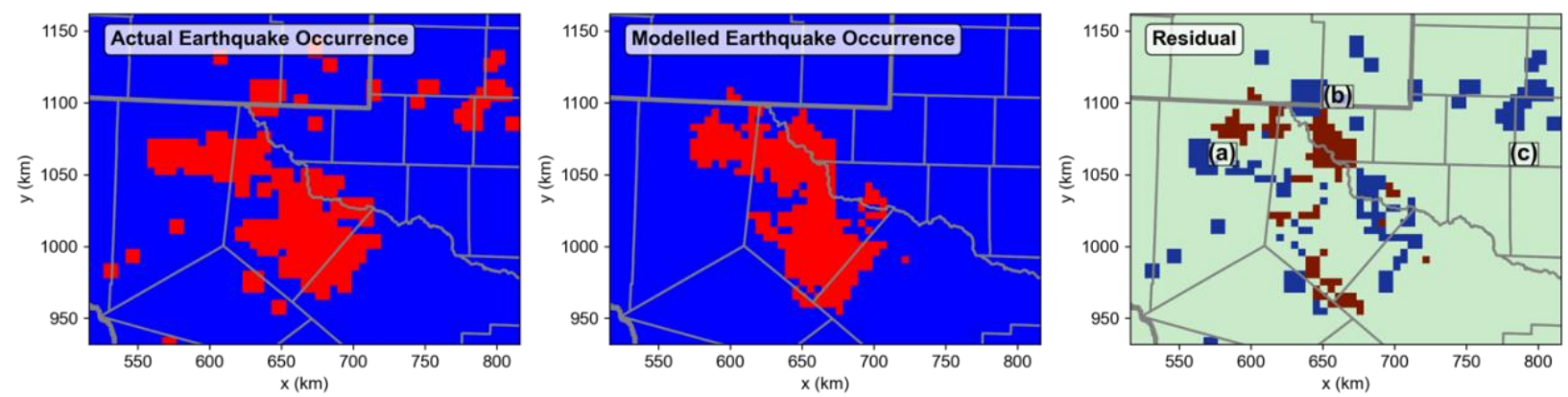
b) Feature coefficients

proximity to closest fault shallow $(\mathrm{km})$ Shallow water Injection / Extraction ( $r=10-25 \mathrm{~km})$ -

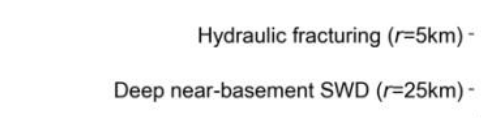

Optimal orientation of basin_subsurface faults -

Deep near-basement SWD ( $r=10 \mathrm{~km})$ Shallow Injection $(r=5 \mathrm{~km})$ -

basement depth $(m)$ -

Production from deep formations $(r=5-10 \mathrm{~km})$ -

Deep near-basement SWD $(r=5 \mathrm{~km})$ -

Total basin_subsurface fault length within $10 \mathrm{~km}$ -

Production from deep formations $(r=5 \mathrm{~km})$

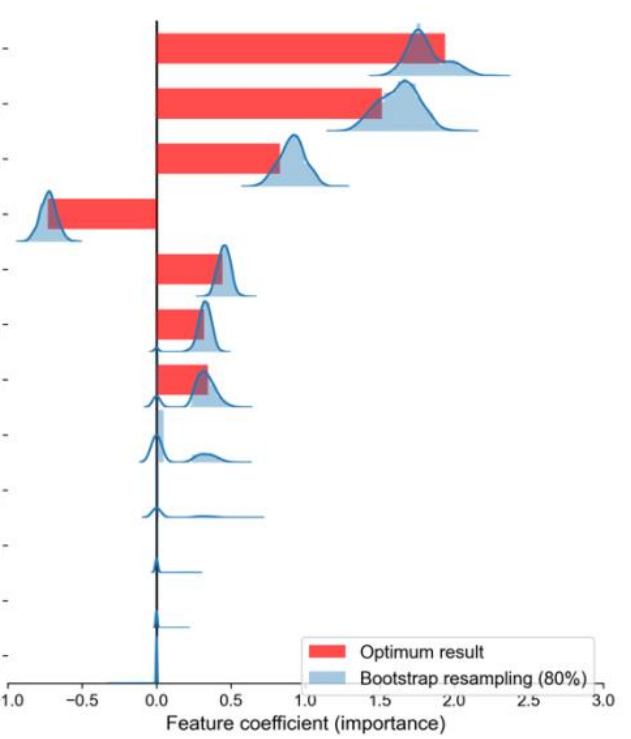

c) Model variance

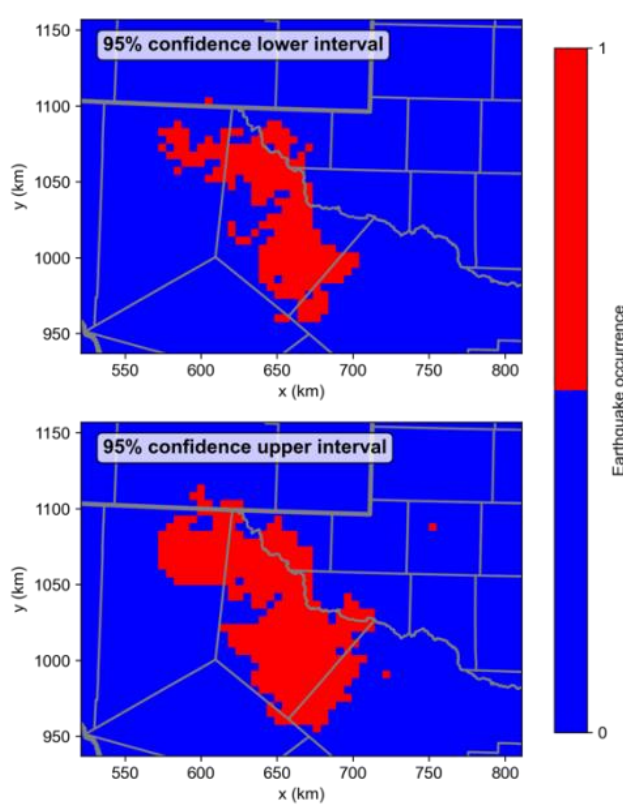

Figure 6: Results from our optimum logistic regression (LR) model. a) Map view of earthquake occurrence (left), which is compared with the model prediction (middle) and the residual between observed and modelled earthquake occurrence (right). Coherent areas of seismicity under- and over-prediction are labelled in the residual plot of panel (a). Label (a) is the Culberson cluster; (b) refers to seismicity along the New Mexico - Texas border area; (c) is the Odessa cluster. These regions with broad residuals are discussed in the text. Panel (b) shows the normalised feature coefficients in the LR model, along with their uncertainty from bootstrap resampling. c) Shows the 95\% confidence bounds on the predictions based on model standard errors.

\subsection{Need for a hybrid industrial and geological model}

To demonstrate that a mixture of industrial and geological factors is needed to explain the spatial distribution of seismicity in the western Permian Basin, we consider two end-member models in which we consider industrial features only and geological features only. The results from these two models are shown in Figure 7. The prevalence of industrial features such as shallow injection/extraction and Wolfcamp HF as per our optimal hybrid model. These industrial features on their own manage to describe the spatial distribution of the main Pecos cluster of seismicity. The industrial features are a stronger overall predictor of seismicity, which is in line with the general hypothesis that earthquake occurrence in the Permian Basin has a significant induced component. However, the proximity to Quaternary faults feature is not prevalent in the geological-only model, implying that this feature works in tandem with the industrial features to reproduce the spatial pattern of seismicity. Although the industrial-only model performs better than the geological-only model, both perform significantly less well than the hybrid model, as shown by the corresponding $r_{p}^{2}$, F1 score, AUROC, AIC, BIC, and MIrvalues ( 
Table 1). Nevertheless, these different end-member models help us to understand how different combinations of features help to explain predicted seismicity distributions.

The Pecos and Odessa clusters correlate quite strongly with HF activity (Figure 4a) and shallow injection/extraction (Figure 4d). The lack of HF on the Central Basin platform likely drives the lack of predicted seismicity here. Deep SWD appears to be quite prevalent in the Odessa region, but this is not a large enough part of our model space to become a significant feature. The basement-rooted faults also appear less well optimally oriented in the Central Basin Platform (Figure 4c). Depth-to-basement is prevalent in the geological-only model; however, this over-predicts seismicity in the south-eastern part of the Delaware Basin where the basin remains deep (Figure 2a), which is why this feature does not appear as a significant one in our hybrid model. 

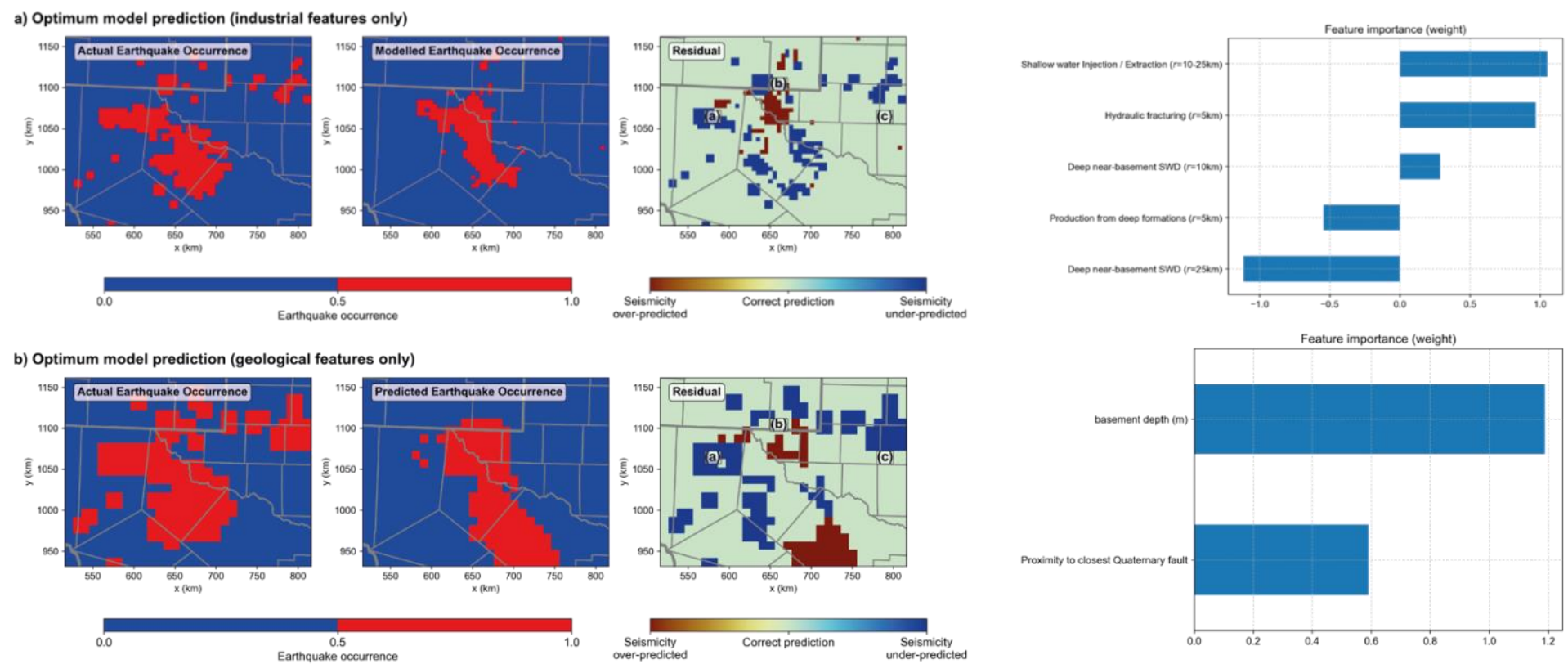

Figure 7: Need for hybrid model features. Models based on industrial features only (top), and geological features only (bottom). The normalized coefficients of the corresponding model features are shown by the horizontal bars 0 the right.

Table 1: Model performance of the four model end-members tested. The preferred and bestperforming model is underlined. AUROC = "area under the receiver operating characteristic".

\begin{tabular}{|l|l|l|l|l|l|l|l|}
\hline Case - features used & $\begin{array}{l}\text { No. } \\
\text { model } \\
\text { features }\end{array}$ & F1 score & $\begin{array}{l}\text { AUROC } \\
\text { score }\end{array}$ & $\mathbf{r}_{\mathbf{p}}$ & $\begin{array}{l}\text { Moran's I- } \\
\text { model residual, } \\
\text { MI }\end{array}$ & AIC & BIC \\
\hline $\begin{array}{l}\text { a) Null hypothesis: } \\
\text { SWD only }\end{array}$ & 1 & 0.000 & 0.500 & 0.018 & 0.690 & 2309 & 2326 \\
\hline $\begin{array}{l}\text { b) Industrial operational } \\
\text { only }\end{array}$ & 5 & 0.488 & 0.673 & 0.286 & 0.521 & 1687 & 1722 \\
\hline c) Geological only & 3 & 0.166 & 0.534 & 0.182 & 0.672 & 1928 & 1951 \\
\hline $\begin{array}{l}\text { d) Industrial + } \\
\text { geological }\end{array}$ & 9 & 0.566 & 0.723 & 0.371 & 0.475 & 1495 & 1554 \\
\hline
\end{tabular}




\section{Discussion of the hybrid logistic regression model}

We find that a combination of industrial and geological features is needed to accurately predict the distribution of seismicity in the western Permian Basin. Although our approach does not allow us to derive definite physical mechanisms of induced seismicity, it permits us to perform hypothesis testing with each of the statistically significant features in our preferred model, considering known triggering mechanisms both in the Permian Basin specifically, and more generally, from the published literature. We discuss each of the features below in order of their significance in the LR model.

\subsection{Significant features of the logistic regression model}

\section{a) Proximity to shallow and recently active faults}

The feature with the largest coefficient in our LR model is a geological parameter: the proximity to shallow and recently active (i.e., Quaternary) faults. This feature particularly helps to reproduce the seismicity at the southwestern edge of the Delaware Basin. This main difference can be seen clearly by comparing the industrial-only and geological-only LR models (Figure 7).

The Delaware Basin is bounded to the west by a series of NNW trending normal faults belonging to the West Delaware Mountain Fault Zone, trending sub-parallel to the Rio Grande rift zone (Collins et al., 1996; Muehlberger et al., 1978). This area has hosted moderate-to-large earthquakes before, such as the $M_{w} 6.3$ Valentine earthquake in 1931 (Doser, 1987; Dumas et al., 1980; Storchak et al., 2013), and a $M_{w} 5.7$ earthquake in 1995. Given that active deformation occurs along the Rio Grande Rift region (Murray et al., 2019), we speculate that the stress associated with this deformation may extend to the Quaternary faults in West Texas. Overall, our results suggest that one key difference between induced seismicity in Oklahoma and Texas is the latter's proximity to recently active faults, and hence west Texas might have stronger pre-existing tectonic stress that may modulate induced earthquakes. The role of these recently active faults has not yet been considered in studies of induced seismicity for the Delaware Basin. 


\section{b) Shallow injection / extraction}

Injection / extraction (search radius $=10-25 \mathrm{~km}$ ) from the shallow Delaware Mountain and Bone Springs Groups is the second most important feature of our LR model. Yet, there is currently little evidence that seismicity is occurring in such shallow layers, although the hypocentral depth distribution of seismicity in the western Permian Basin remains debated. It has been recently suggested by Zhai et al. (2021) that shallow wastewater injection may increase stress on near-basement faults through poroelastic stress transfer. Our LR result provides some additional evidence that such shallow industrial activities may cause seismicity in the Delaware Basin. Moreover, Deng et al. (2020) and Staniewicz et al. (2020) proposed that shallow extraction produces long-term surface subsidence, which aligns with seismicity in the Pecos area, along with uplift from shallow injection, by modelling InSAR observed deformation.

The correlation coefficient between pre-2013 shallow oil production and post-2017 shallow water injection is 0.88 so we cannot confirm the hypothesis of Dvory \& Zoback (2021) that shallow injection into the same formations that were produced from earlier production reduces seismicity rates.

\section{c) Hydraulic fracturing (HF) in the Wolfcamp Shale}

The third most dominant feature in our LR model of earthquake occurrence is the number of HF jobs carried out in the Wolfcamp Shales. Even in the model derived from industrial operational features only (Figure 7), and in a univariate sense (Figure 4), this feature consistently has a strong correlation with earthquake occurrence. Since this feature is highly correlated $(r>0.85)$ with both the oil and water production from the Wolfcamp Shale (Figure 5), we are unable to fully distinguish between numbers of $\mathrm{HF}$ jobs, HF volumes, or the resulting production amounts, although in terms of statistical significance, the number of HF jobs is marginally favoured. HF helps to fit the main clusters of seismicity in the Delaware Basin and in the Odessa region (Figure 4a).

Hydraulic fracturing can trigger seismicity due to localised pore-pressure increases on nearby faults (Schultz et al., 2020). In many documented cases, HF-induced seismicity occurs close $(<5 \mathrm{~km})$ to the injection well and within the same depth range as the shale target formations. However, $\mathrm{HF}$ induced seismicity has also been observed in the basement lying several kilometres beneath the shale target 
formations (Lei et al., 2019). Using a probabilistic distance-time likelihood association of seismicity with well activity, hydraulic fracturing was also shown by Savvaidis et al. (2020) to be one of the main factors causing seismicity in the Delaware basin. Moreover, Dvory \& Zoback (2021) showed that pore pressure perturbations from HF could feasibly trigger shallower seismicity in the Delaware Mountain and Bone Spring Groups. Earthquake depths remain highly uncertain in the Permian Basin, so it is difficult to ascertain whether some earthquakes occur within, above, or below, the Wolfcamp Shales. Even if the seismicity might not be directly related to HF, it remains an important question as to whether production from the Wolfcamp Shale may affect the state of the stress in the deep formations beneath or the shallow formations above. Nevertheless, given the significance of HF in our LR model, we speculate that HF activity affects the stress state in the either the Wolfcamp Shale, or the surrounding formations that encourages seismicity.

\section{d) Deep saltwater disposal (SWD)}

Another feature of the model is the statistical significance of SWD volumes into deep formations, at a radius of $25 \mathrm{~km}$. As opposed to the other features discussed above, this one has a negative coefficient, implying that SWD might impede seismicity within $25 \mathrm{~km}$, although this distance has a high uncertainty since similar results can be obtained using the $10 \mathrm{~km}$ radius. As can be seen in Figure 3 and Figure 4, the largest volume SWD wells are located far to the north of the main Pecos cluster of seismicity, in southern New Mexico. Therefore, there is no straightforward spatial correlation between SWD and seismicity. The negative contribution of SWD most likely helps to reproduce the absence of seismicity on the Central Basin Platform. Since HF activity extends further west than the regions of high-volume SWD, the combined factors help to predict a concentration of seismicity in the Pecos and Mentone regions. Therefore, deep SWD is a spatially clustered feature that helps to replicate the observed pattern of seismicity when combined with other features. Consequently, we cannot say that SWD physically inhibits seismicity across the western Permian Basin. Instead, if anything, it might relate to a unique state-ofstress in the Central Basin platform area. Alternatively, this negative feature may indicate that our model is lacking another feature to explain this seismicity.

Recent studies have made the link between the $2020 M_{w} 4.8$ Mentone earthquake and deep SWD (Skoumal et al., 2021; Tung et al., 2021). However, there are few 
studies (Skoumal \& Trugman, 2021) that link deep SWD to widespread seismicity in the western Permian Basin. Our result of a negative, albeit relatively small, coefficient for deep SWD might imply an aseismic region surrounding high-volume wells, which might be caused by aseismic slip along faults (Guglielmi et al., 2015), a dominance of long-distance poroelastic triggering over near-field pore pressure effects (Goebel et al., 2017), or the distance between large SWD injectors and seismogenic faults.

\section{e) Optimal orientation of basement-rooted faults}

It is reasonably clear that many of the earthquakes that occur in the Delaware Basin do not occur on faulting structures mapped within the basin (Figure 2). For example, in the Pecos region, most mapped basement-rooted faults in the basin strike approximately WNW-ESE, but the seismicity occurs along NW-SE lineations. However, given that the theoretical optimal orientation of these faults (assuming an extensional stress regime, and based on estimates of $S_{H \max }$ ) appears as a statistically significant feature, our results show that the orientation of these faults have mild predictive power and increase the propensity of induced seismicity. Although the mapped faults do not exactly align with the lineations of seismicity (Figure 2), the alignment is close enough to drive the observed correlation in our LR model. It is likely that the faults that host many of the earthquakes in the Permian Basin, which are typically magnitude 4 and less, might be sub-seismic in scale, and hence do not cause the large changes in stratigraphic thickness typically required to be recognised in subsurface datasets.

\subsection{Summary and limitations of our logistic regression model}

Overall, our LR results show that when combined, geological and industrial factors produce a robust correlation with the spatial distribution of seismicity. Although correlation does not equal causation, this method allows us to test some hypotheses for causal factors of induced seismicity which can be discussed and tested with physical models that factor in these different proposed mechanisms. Our approach is highly adaptable to different regions and to different datasets. For example, our method could be expanded to include geodetic maps of deformation. Based on our trained model, we could then expand that Aol to test the stability of model features for a wider region of seismicity in the Permian Basin. Moreover, our method is 
straightforward to update in the event of a new emergent cluster of seismicity, updated industrial operational data, or newly available geological information. Eventually, our approach may help guide regional probabilistic maps of seismogenic potential.

Our approach currently considers the spatial, time-integrated distribution of seismicity and industrial data. Including time-varying features and targets would vastly increase the complexity of such a regression model, but could improve the model fits to certain clusters of seismicity. For example, inter-earthquake triggering (e.g., Coulomb stress transfer) may account for seismicity in the Culberson area, which is not predicted by our model. 


\section{Conclusions}

Using a spatial logistic regression method, we have provided new insights into multivariate statistical correlations with induced seismicity over a large portion of the Permian Basin, Texas, which includes multiple sub-basins. Our work is the first study that we are aware of to consider multiple seismicity clusters across the Permian Basin in a single model. Based on thorough analysis of industrial and geological data, our results demonstrate that a combination of industrial and geological factors is required to predict seismicity in the Permian Basin.

We find that distance to the closest Quaternary fault is a key predictor of the spatial distribution of seismicity. This result indicates that, in contrast to induced seismicity in Oklahoma, a higher rate of background tectonic stress is important in determining the spatial pattern of triggered seismicity in the Permian Basin. Therefore, this higher rate of background tectonic stress should be accounted for when assessing seismicity rates and hazard due to anthropogenic activities in the western Permian Basin. Because earthquake depths in the region remain uncertain, we cannot determine whether direct stress changes from shallow SWD or the indirect changes due to extraction, which could extend to the deep basin and basement, are the main cause of seismicity. Also, in contrast to Oklahoma, it appears that deep SWD is not a dominant factor in determining where induced seismicity occurs. Deep SWD plays a weakly negative role in our model and it likely relates to the lower rate of seismicity on the Central Basin platform, rather than taking a primary role in reducing seismicity overall.

Our modelling approach could be applied to other regions or our model adapted to broader regions, e.g., regions where high volume SWDs exist, but induced seismicity does not occur (Rubinstein \& Mahani, 2015), to identify the reasons for the apparent aseismicity. Such regions include the Williston Basin in North Dakota (Frohlich et al., 2015) and along the Gulf Coast (Weingarten et al., 2015). 


\section{Acknowledgements}

We are grateful to Alexandros Savvaidis for fruitful discussions on the TexNet earthquake catalogue. We also thank Iason Grigoratos and Ellen Rathje for fruitful discussions. This manuscript was improved with thorough reviews by Daniel Trugman and Ryan Schultz. This study was made possible through a donation of data from IHS Markit.

\section{Data availability statement}

Well metadata and monthly production / injection data are available through the IHS Markit Well Database (https://ihsmarkit.com/products/us-well-data.html), which consists of records, including but not limited to The Railroad Commission of Texas (www.rrc.texas.gov). Hydraulic fracturing data are available through the FracFocus database (https://fracfocus.org).

The TexNet seismicity catalogue is available from http://www.beg.utexas.edu/texnetcisr/texnet/earthquake-catalog and the New Mexico Tech catalogue can be obtained from https://geoinfo.nmt.edu/nmtso/events/home.cfml.

Software used in the analysis of this study and to produce figures includes the following Python packages: scikit-learn (Pedregosa et al., 2011); ObsPy (Krischer et al., 2015); matplotlib (Hunter, 2007); statsmodels (Seabold \& Perktold, 2010); cartopy (Met Office, 2010); and seaborn (Waskom, 2021). 


\section{References}

Akaike, H. (1974). A new look at the statistical model identification. IEEE Transactions on Automatic Control, 19(6), 716-723.

Chicco, D., \& Jurman, G. (2020). The advantages of the Matthews correlation coefficient (MCC) over F1 score and accuracy in binary classification evaluation. BMC Genomics, 21(1), 6. https://doi.org/10.1186/s12864-0196413-7

Cochran, E. S., Ross, Z. E., Harrington, R. M., Dougherty, S. L., \& Rubinstein, J. L. (2018). Induced Earthquake Families Reveal Distinctive Evolutionary Patterns Near Disposal Wells. Journal of Geophysical Research: Solid Earth, 123(9), 8045-8055. https://doi.org/10.1029/2018JB016270

Collins, E. W., Raney, J. A., Machette, M. N., Haller, K. M., \& Dart, R. L. (1996). Map and data for Quaternary faults in West Texas and adjacent parts of Mexico. US Department of the Interior, US Geological Survey.

Comer, J. B. (1991). Stratigraphic analysis of the upper Devonian Woodford formation, Permian basin, west Texas and southeastern New Mexico (Vol. 201). Bureau of Economic Geology, University of Texas at Austin.

Cox, D. R. (1958). The Regression Analysis of Binary Sequences. Journal of the Royal Statistical Society: Series B (Methodological), 20(2), 215-232. https://doi.org/10.1111/j.2517-6161.1958.tb00292.x

Deng, F., Dixon, T. H., \& Xie, S. (2020). Surface Deformation and Induced Seismicity Due to Fluid Injection and Oil and Gas Extraction in Western Texas. Journal of Geophysical Research: Solid Earth, 125(5), e2019JB018962. https://doi.org/10.1029/2019JB018962 
Domencich, T. A., \& McFadden, D. (1975). Statistical estimation of choice probability functions. Urban Travel Demand. A Behavioral Analysis. North-Holland Publishing Company, New York, 101-125.

Doser, D. I. (1987). The 16 August 1931 Valentine, Texas, earthquake: Evidence for normal faulting in west Texas. Bulletin of the Seismological Society of America, 77(6), 2005-2017.

Doser, D. I., Baker, M. R., \& Mason, D. B. (1991). Seismicity in the War-Wink gas field, Delaware Basin, west Texas, and its relationship to petroleum production. Bulletin of the Seismological Society of America, 81(3), 971-986. Retrieved from https://pubs.geoscienceworld.org/ssa/bssa/articleabstract/81/3/971/119512/Seismicity-in-the-War-Wink-gas-field-Delaware

Doser, D. I., Baker, M. R., Luo, M., Marroquin, P., Ballesteros, L., Kingwell, J., et al. (1992). The not so simple relationship between seismicity and oil production in the Permian Basin, west Texas. Pure and Applied Geophysics, 139(3), 481-506. https://doi.org/10.1007/BF00879948

Dumas, D. B., Dorman, H. J., \& Latham, G. V. (1980). A reevaluation of the August 16, 1931 Texas earthquake. Bulletin of the Seismological Society of America, 70(4), 1171-1180. Retrieved from https://pubs.geoscienceworld.org/ssa/bssa/articleabstract/70/4/1171/118080/A-reevaluation-of-the-August-16-1931-Texas

Dundon, L. A., Abkowitz, M., \& Camp, J. (2015). The real value of FracFocus as a regulatory tool: A national survey of state regulators. Energy Policy, 87, 496504. https://doi.org/10.1016/j.enpol.2015.09.031 
Dvory, N. Z., \& Zoback, M. D. (2021). Prior oil and gas production can limit the occurrence of injection-induced seismicity: A case study in the Delaware Basin of western Texas and southeastern New Mexico, USA. Geology. https://doi.org/10.1130/G49015.1

Ellsworth, W. L. (2013). Injection-Induced Earthquakes. Science, 341(6142). https://doi.org/10.1126/science.1225942

Ewing, T., Henry, C., Jackson, M., Woodruff Jr, C., Goldstein, A., \& Garrison Jr, J. (1983). Tectonic Map of Texas-A Progress Report. AAPG Bulletin, 67(3), 458-458.

Fawcett, T. (2006). An introduction to ROC analysis. Pattern Recognition Letters, 27(8), 861-874. https://doi.org/10.1016/j.patrec.2005.10.010

Frohlich, C., Walter, J. I., \& Gale, J. F. W. (2015). Analysis of Transportable Array (USArray) Data Shows Earthquakes Are Scarce near Injection Wells in the Williston Basin, 2008-2011. Seismological Research Letters, 86(2A), 492499. https://doi.org/10.1785/0220140180

Frohlich, C., Hayward, C., Rosenblit, J., Aiken, C., Hennings, P., Savvaidis, A., et al. (2020). Onset and Cause of Increased Seismic Activity Near Pecos, West Texas, United States, From Observations at the Lajitas TXAR Seismic Array. Journal of Geophysical Research: Solid Earth, 125(1), e2019JB017737. https://doi.org/10.1029/2019JB017737

Goebel, T. H. W., Weingarten, M., Chen, X., Haffener, J., \& Brodsky, E. E. (2017). The 2016 Mw5.1 Fairview, Oklahoma earthquakes: Evidence for long-range poroelastic triggering at $>40 \mathrm{~km}$ from fluid disposal wells. Earth and Planetary Science Letters, 472, 50-61. https://doi.org/10.1016/j.epsl.2017.05.011 
Guglielmi, Y., Cappa, F., Avouac, J.-P., Henry, P., \& Elsworth, D. (2015). Seismicity triggered by fluid injection-induced aseismic slip. Science, 348(6240), 12241226. https://doi.org/10.1126/science.aab0476

Hincks, T., Aspinall, W., Cooke, R., \& Gernon, T. (2018). Oklahoma's induced seismicity strongly linked to wastewater injection depth. Science, 359(6381), 1251-1255. https://doi.org/10.1126/science.aap7911

Horne, E., Hennings, P., \& Zahm, C. (2021). Basement-rooted faults of the Delaware Basin and Central Basin Platform, Permian Basin, West Texas and southeastern New Mexico. In The Geologic Basement of Texas: A Volume in Honor of Peter T. Flawn. https://doi.org/10.23867/RI0286C6

Hunter, J. D. (2007). Matplotlib: A 2D graphics environment. Computing in Science \& Engineering, 9(3), 90-95. https://doi.org/10.1109/MCSE.2007.55

James, G., Witten, D., Hastie, T., \& Tibshirani, R. (2013). An introduction to statistical learning (Vol. 112). Springer.

Jessee, M. A. N., Hamburger, M. W., Allstadt, K., Wald, D. J., Robeson, S. M., Tanyas, H., et al. (2018). A Global Empirical Model for Near-Real-Time Assessment of Seismically Induced Landslides. Journal of Geophysical Research: Earth Surface, 123(8), 1835-1859. https://doi.org/10.1029/2017JF004494

Keranen, \& Weingarten, M. (2018). Induced Seismicity. Annual Review of Earth and Planetary Sciences, 46(1), 149-174. https://doi.org/10.1146/annurev-earth082517-010054

Keranen, Weingarten, M., Abers, Geoffrey A., Bekins, B. A., \& Ge, S. (2014). Sharp increase in central Oklahoma seismicity since 2008 induced by massive 
wastewater injection. Science, 345(6195), 448-451.

https://doi.org/10.1126/science.1255802

Kim, W.-Y. (2013). Induced seismicity associated with fluid injection into a deep well in Youngstown, Ohio. Journal of Geophysical Research: Solid Earth, 118(7), 3506-3518. https://doi.org/10.1002/jgrb.50247

Krischer, L., Megies, T., Barsch, R., Beyreuther, M., Lecocq, T., Caudron, C., \& Wassermann, J. (2015). ObsPy: a bridge for seismology into the scientific Python ecosystem. Computational Science \& Discovery, 8(1), 014003. https://doi.org/10.1088/1749-4699/8/1/014003

Lei, X., Wang, Z., \& Su, J. (2019). The December 2018 ML 5.7 and January 2019 ML 5.3 Earthquakes in South Sichuan Basin Induced by Shale Gas Hydraulic Fracturing. Seismological Research Letters, 90(3), 1099-1110. https://doi.org/10.1785/0220190029

Lemons, C. R., McDaid, G., Smye, K. M., Acevedo, J. P., Hennings, P. H., Banerji, D. A., \& Scanlon, B. R. (2019). Spatiotemporal and stratigraphic trends in saltwater disposal practices of the Permian Basin, Texas and New Mexico, United States. Environmental Geosciences, 26(4), 107-124. https://doi.org/10.1306/eg.06201919002

Lomax, A., \& Savvaidis, A. (2019). Improving Absolute Earthquake Location in West Texas Using Probabilistic, Proxy Ground-Truth Station Corrections. Journal of Geophysical Research: Solid Earth, 124(11), 11447-11465. https://doi.org/10.1029/2019JB017727 
Lund Snee, J.-E., \& Zoback, M. D. (2016). State of stress in Texas: Implications for induced seismicity. Geophysical Research Letters, 43(19), 10,208-10,214. https://doi.org/10.1002/2016GL070974

Lund Snee, J.-E., \& Zoback, M. D. (2020). Multiscale variations of the crustal stress field throughout North America. Nature Communications, 11(1), 1951. https://doi.org/10.1038/s41467-020-15841-5

McFadden, D. (1973). Conditional logit analysis of qualitative choice behavior. Met Office. (2010). Cartopy: a cartographic python library with a matplotlib interface. Exeter, Devon. Retrieved from http://scitools.org.uk/cartopy

Midi, H., Sarkar, S. K., \& Rana, S. (2010). Collinearity diagnostics of binary logistic regression model. Journal of Interdisciplinary Mathematics, 13(3), 253-267. https://doi.org/10.1080/09720502.2010.10700699

Moran, P. A. (1950). Notes on continuous stochastic phenomena. Biometrika, $37(1 / 2), 17-23$.

Muehlberger, W. R., Belcher, R. C., \& Goetz, L. K. (1978). Quaternary faulting in Trans-Pecos Texas. Geology, 6(6), 337-340. https://doi.org/10.1130/00917613(1978)6<337:QFITT>2.0.CO;2

Murray, K. D., Murray, M. H., \& Sheehan, A. F. (2019). Active Deformation Near the Rio Grande Rift and Colorado Plateau as Inferred from Continuous Global Positioning System Measurements. Journal of Geophysical Research: Solid Earth, 124(2), 2166-2183. https://doi.org/10.1029/2018JB016626

Norbeck, J. H., \& Rubinstein, J. L. (2018). Hydromechanical Earthquake Nucleation Model Forecasts Onset, Peak, and Falling Rates of Induced Seismicity in 
Oklahoma and Kansas. Geophysical Research Letters, 45(7), 2963-2975. https://doi.org/10.1002/2017GL076562

Nowicki, M. A., Wald, D. J., Hamburger, M. W., Hearne, M., \& Thompson, E. M. (2014). Development of a globally applicable model for near real-time prediction of seismically induced landslides. Engineering Geology, 173, 5465. https://doi.org/10.1016/j.enggeo.2014.02.002

Pankow, K. L., Stickney, M., Ben-Horin, J. Y., Litherland, M., Payne, S., Koper, K. D., et al. (2019). Regional Seismic Network Monitoring in the Eastern Intermountain West. Seismological Research Letters, 91(2A), 631-646. https://doi.org/10.1785/0220190209

Pawley, S., Schultz, R., Playter, T., Corlett, H., Shipman, T., Lyster, S., \& Hauck, T. (2018). The Geological Susceptibility of Induced Earthquakes in the Duvernay Play. Geophysical Research Letters, 45(4), 1786-1793. https://doi.org/10.1002/2017GL076100

Pedregosa, F., Varoquaux, G., Gramfort, A., Michel, V., Thirion, B., Grisel, O., et al. (2011). Scikit-learn: Machine Learning in Python. Journal of Machine Learning Research, 12, 2825-2830.

Raleigh, C. B., Healy, J. H., \& Bredehoeft, J. D. (1976). An Experiment in Earthquake Control at Rangely, Colorado. Science, 191(4233), 1230-1237. https://doi.org/10.1126/science.191.4233.1230

Ries, R., Brudzinski, M. R., Skoumal, R. J., \& Currie, B. S. (2020). Factors Influencing the Probability of Hydraulic Fracturing-Induced Seismicity in Oklahoma. Bulletin of the Seismological Society of America, 110(5), 22722282. https://doi.org/10.1785/0120200105 
Robinson, R., Li, A., Savvaidis, A., \& Hu, H. (2020). Complex Shear-Wave Anisotropy from Induced Earthquakes in West Texas. Bulletin of the Seismological Society of America, 110(5), 2242-2251. https://doi.org/10.1785/0120200086

Rubinstein, J. L., \& Mahani, A. B. (2015). Myths and Facts on Wastewater Injection, Hydraulic Fracturing, Enhanced Oil Recovery, and Induced Seismicity. Seismological Research Letters, 86(4), 1060-1067. https://doi.org/10.1785/0220150067

Rubinstein, J. L., Ellsworth, W. L., \& Dougherty, S. L. (2018). The 2013-2016 Induced Earthquakes in Harper and Sumner Counties, Southern Kansas. Bulletin of the Seismological Society of America, 108(2), 674-689. https://doi.org/10.1785/0120170209

Savvaidis, A., Young, B., Huang, G. D., \& Lomax, A. (2019). TexNet: A Statewide Seismological Network in Texas. Seismological Research Letters, 90(4), 1702-1715. https://doi.org/10.1785/0220180350

Savvaidis, A., Lomax, A., \& Breton, C. (2020). Induced Seismicity in the Delaware Basin, West Texas, is Caused by Hydraulic Fracturing and Wastewater Disposal. Bulletin of the Seismological Society of America, 110(5), 22252241.

Schultz, R., Skoumal, R. J., Brudzinski, M. R., Eaton, D., Baptie, B., \& Ellsworth, W. (2020). Hydraulic Fracturing-Induced Seismicity. Reviews of Geophysics, 58(3), e2019RG000695. https://doi.org/10.1029/2019RG000695

Schwarz, G. (1978). Estimating the dimension of a model. Annals of Statistics, 6(2), $461-464$. 
Seabold, S., \& Perktold, J. (2010). statsmodels: Econometric and statistical modeling with python. In 9th Python in Science Conference.

Segall, P., \& Lu, S. (2015). Injection-induced seismicity: Poroelastic and earthquake nucleation effects. Journal of Geophysical Research: Solid Earth, 120(7), 5082-5103. https://doi.org/10.1002/2015JB012060

Sibson, R. H. (1990). Rupture nucleation on unfavorably oriented faults. Bulletin of the Seismological Society of America, 80(6A), 1580-1604.

Simpson, R. W. (1997). Quantifying Anderson's fault types. Journal of Geophysical Research: Solid Earth, 102(B8), 17909-17919.

https://doi.org/10.1029/97JB01274

Skoumal, R. J., \& Trugman, D. T. (2021). The Proliferation of Induced Seismicity in the Permian Basin, Texas. Journal of Geophysical Research: Solid Earth, 126(6), e2021JB021921. https://doi.org/10.1029/2021JB021921

Skoumal, R. J., Ries, R., Brudzinski, M. R., Barbour, A. J., \& Currie, B. S. (2018). Earthquakes Induced by Hydraulic Fracturing Are Pervasive in Oklahoma. Journal of Geophysical Research: Solid Earth, 123(12), 10,918-10,935. https://doi.org/10.1029/2018JB016790

Skoumal, R. J., Brudzinski, M. R., \& Currie, B. S. (2018). Proximity of Precambrian basement affects the likelihood of induced seismicity in the Appalachian, Illinois, and Williston Basins, central and eastern United States. Geosphere, 14(3), 1365-1379. https://doi.org/10.1130/GES01542.1

Skoumal, R. J., Barbour, A. J., Brudzinski, M. R., Langenkamp, T., \& Kaven, J. O. (2020). Induced seismicity in the Delaware Basin, Texas. Journal of Geophysical Research: Solid Earth, 125(1), e2019JB018558. 
Skoumal, R. J., Kaven, J. O., Barbour, A. J., Wicks, C., Brudzinski, M. R., Cochran, E. S., \& Rubinstein, J. L. (2021). The Induced Mw 5.0 March 2020 West Texas Seismic Sequence. Journal of Geophysical Research: Solid Earth, 126(1), e2020JB020693. https://doi.org/10.1029/2020JB020693

Staniewicz, S., Chen, J., Lee, H., Olson, J., Savvaidis, A., Reedy, R., et al. (2020). InSAR Reveals Complex Surface Deformation Patterns Over an 80,000 km2 Oil-Producing Region in the Permian Basin. Geophysical Research Letters, 47(21), e2020GL090151. https://doi.org/10.1029/2020GL090151

Stine, R. A. (1995). Graphical Interpretation of Variance Inflation Factors. The American Statistician, 49(1), 53-56. https://doi.org/10.1080/00031305.1995.10476113

Storchak, D. A., Di Giacomo, D., Bondár, I., Engdahl, E. R., Harris, J., Lee, W. H. K., et al. (2013). Public Release of the ISC-GEM Global Instrumental Earthquake Catalogue (1900-2009). Seismological Research Letters, 84(5), 810-815. https://doi.org/10.1785/0220130034

Teng, G., \& Baker, J. W. (2020). Short-Term Probabilistic Hazard Assessment in Regions of Induced Seismicity. Bulletin of the Seismological Society of America, 110(5), 2441-2453. https://doi.org/10.1785/0120200081

van Thienen-Visser, K., \& Breunese, J. N. (2015). Induced seismicity of the Groningen gas field: History and recent developments. The Leading Edge, 34(6), 664-671. https://doi.org/10.1190/tle34060664.1

Trugman, D. T., \& Savvaidis, A. (2021). Source Spectral Properties of Earthquakes in the Delaware Basin of West Texas. Seismological Research Letters, 92(4), 2477-2489. https://doi.org/10.1785/0220200461 
Tung, S., Zhai, G., \& Shirzaei, M. (2020). Potential link between 2020 Mentone, West Texas M5 earthquake and nearby wastewater injection: implications for aquifer mechanical properties. Geophysical Research Letters, n/a(n/a), 2020GL090551. https://doi.org/10.1029/2020GL090551

Tung, S., Zhai, G., \& Shirzaei, M. (2021). Potential Link Between 2020 Mentone, West Texas M5 Earthquake and Nearby Wastewater Injection: Implications for Aquifer Mechanical Properties. Geophysical Research Letters, 48(3), e2020GL090551. https://doi.org/10.1029/2020GL090551

Waskom, M. L. (2021). seaborn: statistical data visualization. Journal of Open Source Software, 6(60), 3021. https://doi.org/10.21105/joss.03021

Weingarten, M., Ge, S., Godt, J. W., Bekins, B. A., \& Rubinstein, J. L. (2015). Highrate injection is associated with the increase in U.S. mid-continent seismicity. Science, 348(6241), 1336-1340. https://doi.org/10.1126/science.aab1345

Wozniakowska, P., \& Eaton, D. W. (2020). Machine Learning-Based Analysis of Geological Susceptibility to Induced Seismicity in the Montney Formation, Canada. Geophysical Research Letters, 47(22), e2020GL089651. https://doi.org/10.1029/2020GL089651

Yeo, I.-K., \& Johnson, R. A. (2000). A new family of power transformations to improve normality or symmetry. Biometrika, 87(4), 954-959.

Yixiao Sheng, Ellsworth, W. L., \& Pepin, K. S. S. (2020). On the Depth of Earthquakes in the Delaware Basin-A Case Study along the Reeves-Pecos County line. In AGU Fall Meeting Abstracts (Vol. 2020, pp. S013-0007).

Zhai, G., Shirzaei, M., Manga, M., \& Chen, X. (2019). Pore-pressure diffusion, enhanced by poroelastic stresses, controls induced seismicity in Oklahoma. 
Proceedings of the National Academy of Sciences, 116(33), 16228-16233. https://doi.org/10.1073/pnas.1819225116

Zhai, G., Shirzaei, M., \& Manga, M. (2021). Widespread deep seismicity in the Delaware Basin, Texas, is mainly driven by shallow wastewater injection. Proceedings of the National Academy of Sciences, 118(20). https://doi.org/10.1073/pnas.2102338118 